\title{
Profiles in Cardiac Electrophysiology
}

\author{
Albert L. Waldo MD, PhD (Hon) \\ Department of Medicine, Case Western Reserve University; Harrington Heart \& Vascular Institute, University Hospitals Case Medical \\ Center, Division of Cardiovascular Medicine; Cleveland, Ohio, USA
}

\section{Key Words}

\section{Advances in cardiac electrophysiology • Biography • Leaders \\ Copyright @ 2015 Science International Corp.}

In our lifetimes, we have witnessed dramatic developments and enormous growth in cardiac EP powered by giants working in institutions that have trained generations of leaders, by scientific discoveries and even by chance events. Fueling this growth have been many things. And interestingly, those behind some of the most groundbreaking events may not have completely grasped the profundity of their ideas at that moment. Nevertheless, these changes almost surely occurred in a community of colleagues who contributed in their own way, and helped provide a platform in which new thinking emerged.

In "Profiles in EP'" we plan to invite colleagues to share their stories of how their ideas, discoveries, and developments came to be or to share how their institution came to figure so prominently in developing EP. It is the intent of this column to grasp the essence of discovery from leaders in our profession, and inspire the reader. We also plan to profile the many laboratories and people who have contributed to the advancement of our field.

EP did not happen by accident. How did new ideas and concepts develop? What was the setting? What was the motivation? What was the support? Was it planned, or simply an accident? For those who have advanced the field, upon whose work did they build, and to whom do they owe their success? Do they even consider their work to be a success? What inspired them?

We hope to capture how these Eureka! moments actually happened, and even provide stimulus for continued exploration. Numerous developments have changed our understanding of so many things from basic concepts to nuances of catheter ablation and device development. Nowhere in medicine has innovation and growth been this spectacular, and for so long a period, even preceding our time. The remarkable discoveries date back over a century, and have placed cardiac electrophysiology in a unique place in medicine and science.

For many of us, the scientific and technological developments, and the kind of creative minds behind these discoveries, are part of the reason we have chosen this field. Younger colleagues may wonder how these insights came to be. Is the field now mature and staid, or can a way still be found to contribute to its escalating growth, and if so, how?

The truth of the matter is that we are only at the beginning of a tremendous journey that requires bright minds to explore hitherto unknown possibilities in the field that one day may become reality. We are enriched by having talented friends and colleagues to usher us through this continuing adventure in which a special part is simply getting up in the morning to find new tools to better treat our patients.

This column will focus on the "magic" that leads
() 2015 Arrhythmia Grand Rounds Published by Science International Corp. ISSN 2326-4012

Accessible online at: http://arrhythmiagr.com/
* Corresponding Author:

Albert L. Waldo MD, PhD (Hon)

Harrington Heart \& Vascular Institute, Division of Cardiovascular Medicine University Hospitals Case Medical Center

11100 Euclid Ave, Cleveland, Ohio 44106, USA

Tel. +1 216844 7690, Fax: +1 216844 7196, E-Mail: albert.waldo@case.edu 
to discovery, and on how we can continue with new stories and new visions. As Marcel Proust said: "The real voyage of discovery consists not in seeing new landscapes but in having new eyes." We hope this column will provide an important part of the history of our field, and even be an inspiration for its further growth.

\section{Comment on this Article or Ask a Question}

Cite this article as: Waldo AL. Profiles in Electrophysiology. Arrhythmia Grand Rounds 2015;1(1): 42-43. DOI: http://dx.doi. org/10.12945/j.agr.2015.00023-14 